\title{
Determination of Optimal River Network from DEM using differential GPS
}

\author{
Ibrahim Muhammed ${ }^{1}$, Daniel David ${ }^{2}$ \\ ${ }^{1}$ Department of Surveying and Geo-informatics, School of Environmental Sciences, \\ Modibbo Adama University of Technology, PMB 2076 Yola, Adamawa State, Nigeria.
}

\begin{abstract}
In this study, the Optimal River Network (ORN) has been determined in a waterlogged area. A dense $3 D$ coordinates obtained from Differential GPS were used to create a Digital Elevation and Digital Terrain Models and their contingents comprising Watershed, Slope, Contours and Aspect. Areas at risk of being flooded are northward, surrounded by lowlying terrain while the south constitute undulating hills with natural river discharge at the centre. The ORN determines an ideal direction of flow of water out of the region, putting into consideration future planning and development. Existing small streams are directed to a permanent flow network to minimise land loss due to erosion and reduce cost of developing building projects in the waterlogged area. It is evident here that Differential GPS and Geographic Information Systems software can be combined to find ideal solutions to natural hazards akin to flood and erosion and even beyond.
\end{abstract}

Keywords : Flood, DEM, Watershed, GIS, Differential GPS

\section{INTRODUCTION}

Floods constitute hazards and are a form of land degradation. These results in homes being washed away and in some severe cases, a whole community could be submerged. Victims of flood are mostly downstream where large water volumes flows to. The causes of flood are tied to changes in climate, location of built-up areas (e.g. at a particular terrain), the geology of the soils, vegetation cover etc. Floods are also caused by tidal anomalies at coastal areas, especially were wavebreaks are poorly constructed.

When there is a heavy downpour within a short period of time resulting in rainfall excess, existing drainage capacity could not adequately take it, leading to a stagnation of surface runoff for some period leading to flooding (Ward , 1978). In the developing world, poor planning and inadequate drainage systems are the main causes. In this case human interference is viewed in the context of urbanization resulting in a new physical landscape and a new ecosystem (Akintola, 1978). In addition, tsunamis can also cause an unprecedented overflow of water at the coastal areas leading to serious damage to coastal communities.

The assesment of coastal flood risks in a particular region reguire the estimation of typical damages caused by storm surges of certain characteristics and annualities. Although the damage depends on a multitude of factors, including flow velocity, duration of flood etc (Boettle et al., 2011). Floods may not be completely eradicated but can be minimised when certain measures are taken. Previously, traditional surveying methods have been used to map out areas liable to flood. In recent years, more sophisticated instruments involving aerial surveys, Global Positioning Systems (GPS) and satellite images are used to plan against floods before they occur.

Flood mapping processes that consider topography are either flood plain mapping or stream flow mapping. The latter considers drainage. Unlike flood plain mapping that involved a large area as flood hazard zones, the application of stream flow provides exact areas where drainages can be made. In this paper, Digital Elevation Model (DEM) is constructed to show flood plains and produce Optimal River Network (ORN).

DEMs represent terrain's surface in three-dimentional perspective in which man-made features and vegetations are included. It can also be used to represent surfaces of other planets such as the moon or asteroids (Mark, 1988; Podobnikar, 2008). DEMs are differentiated from other models in that, they show accurately how the morphology is presented. They are used in Geographic Information Systems (GIS), and are the most common basis for digitally-produced relief maps.

DEMs imply that elevation is available continously at each location in a study area. They are used for extracting terrain parameters, modelling water flow or mass movement (for example, avalanches and slides), creation of relief maps and rendering of 3-D visualizations etc.

Various methods have been used to determine three-dimensional positions of terrains for a variety of applications. These include traditional surveying involving the use of instruments such as theodolites, levels, total stations, topographic maps from aerial photography, surveying and mapping drones etc. Digital photogrammetry involving block adjustment from optical satellite imagery is also used to derive DEM. The use of Light Detection and Ranging (LiDAR), Interferometric Synthetic Aperture Radar (IfSAR) and satellite mapping such as GTOPO, SRTM, ASTER GDEM1, ASTER GDEM2 are very common nowadays (Li et al., 
2005). Others include the use of Differential Global Positioning Systems (DGPS) and a GIS, as is the case with this paper.

The DGPS uses a relative positioning and gives an accuracy of the order of $10 \mathrm{~cm}$ to $15 \mathrm{~cm}$ (Konecny, 2003). This is achieved by accelerometers for which the signals are integrated in an Inertial Measuring Unit (IMU). The operation of DGPS is that, a master GPS receiver is utilized at a geodetic reference station. It receives the same satellite signals observed at a transportable second receiver (rover), which is used for the measurements at new point locations.

Computer aided automatic extraction of drainage networks for DEMs can promote the efficiency of regional water resources prospecting and assesment in GIS. Extraction of drainage networks from raster DEMs and determining surface water flow of the areas is a neccessary reguirement in many GIS applications. In general, it is important in monitoring and managing natural resources, monitoring natural harzards and spatial decision making. Usually, DEM is built by interpolation from a limited set of sample points to form a smooth 3D surface. Other DEM contingents such as Watersheds, Slopes, Aspects and Contours are further considered to obtain a permanent drainage network.

This paper aims to provide an Optimal River Network (ORN) in a lowlying and seasonally waterlogged Barama Plains in Mubi Town, Mubi North Local Government Area of Adamawa State, Nigeria using DEM and its contingents. The paper is organised as follows: 1) Introduction, 2) Methodology, 3) Results and Discussion, and 4) Conclusions and Recommendations.

\section{DATA AND METHOD}

The Digital Elevation Model and its contingents are produced from highly densed 3D coordinates collected from Differential GPS (Leica SR20). The essence of collecting dense and close data points is to provide as much accuracy as possible of the surface terrain during DEM generation and subsiquent works. This will allow accurate determination of the drainage network. A tape was used to measure the heights of the instruments to avoid ambiguity in the overrall results arising from varying heights of master and rover instruments. ArcGIS version 9.3 and Global Mapper were then used to process the results, that include DEM, Watershed, Slope, Contour and Aspect.

\subsection{Generation of DEM}

If elevation data are available only through topographic maps, for example the topo map, then it is possible to generate DEM by scanning the topo map and digitising off the contours. Interpolation procedure using appropriate software can then be appied to smooth the surface. In our case, generation of DEM is automatic. The 3D DGPS coordinates are imported into ArcGIS and the DEM is generated (figure 1a). This is achieved by ordinary Kridging in ArcGIS, and choosing this technique gives higher precision even if the area is small (Kumura, 2008). This is because Kridging provides a fine-scale interpolation leading to an almost smooth surface.

\subsection{Generation of Watershed Map}

To produce watershed map, the spatial toolbox in ArcGIS is used. This map represents flow accumulation by making use of each pixel from the DEM. To do this, watershed calculates all cells directly in view of a set of target cells specified on a separate image. To do so, viewshed extends visual rays in all directions and traces the line of sight to the height of cells to determine whether or not they are in view (ESRI, 2003). The outlets of the largest streams, rivers etc will have the largest values. However, the watershed has other characteristics that need to be studied, that include gradient and steepness represented by Slope Map and flow direction represented by Aspect Map (Bukhari and Muhammed, 2013).

\subsection{Generation of Slope Map}

The Slope is expressed as an azimuth, that is an angle measured clockwise from north. Hence, it gives the altitude of the terrain surface. To calculate slope maps in percentages and in degrees, equation 1 is used.

$$
\alpha=\operatorname{rad} 2 \operatorname{deg}\left[\arctan \left(\Delta H * \frac{\Sigma L}{A}\right)\right]
$$

where $\alpha=$ Slope, $\Delta H=$ Contour Interval, $\Sigma L=$ total length of contours in the area, and $A$ is the size of the area. The reason for the conversion is that azimuths are better understood as in degrees than in radians. 


\subsection{Creation of Contour Map}

Contours are one of the several common methods used to denote elevation or altitude and depth on map. To create contour map, spatial analyst tool box was used using the contour module in ArcGIS. In order to obtain the vector isolines of constant value on the raster image, we specified $1 \mathrm{~m}$ contour interval. The resulting vector file helps us to enhance visualization of continuous surface topography and to enable us view areas of strong variations in height (Figure 2a). The DGPS scale or map scale is $1: 5,000 \mathrm{~m}$.
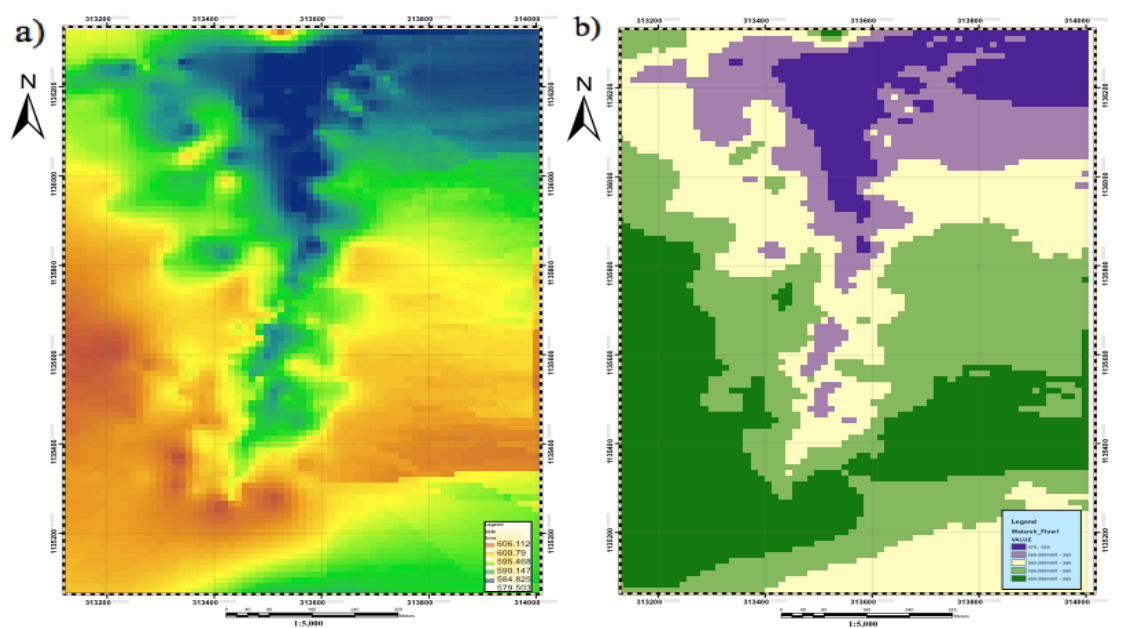

Figure 1: Maps of the study area showing a) Digital Elevation Model, with scales showing hills as red and lowlands as blue, and b) Watershed map showing where water easily drain to (purple).

\subsection{Creation of Aspect Map}

Aspect Map is also called Flow Direction Map, and it shows a region of maximum descend that is evaluated from the DEM. The word Aspect is defined as the direction of the biggest slope vector on the tangent plane projected onto the horizontal plane. Aspect is the bearing (or azimuth) of the slope direction, and its angle ranges from 0 to $360^{\circ}$ in a clockwise direction ( $\mathrm{Li}$ et al, 2004). Aspect is computed from the directional slopes (where $\alpha=$ Slope) obtained, using equation 2 .

$$
\beta=\operatorname{rad} 2 \operatorname{deg}\left[\arctan \left(\frac{\alpha \mathrm{Col}}{\alpha \text { Row }}\right)\right]
$$

The flow direction operation as indicated from the Aspect Map (Figure 2b) determines into which neighbouring pixel, any water in a central pixel will flow naturally.

\subsection{Drainage Map}

The drainage network was produced using Global mapper software and it was achieved by inputing the DEM of the study area into the Global mapper. After creating watershed map, fill depth of the stream was specified and the drainage was automatically produced on the DEM. The blue lines overlaid on the DEM (Figure 3b) indicate the Optimal River Network. 

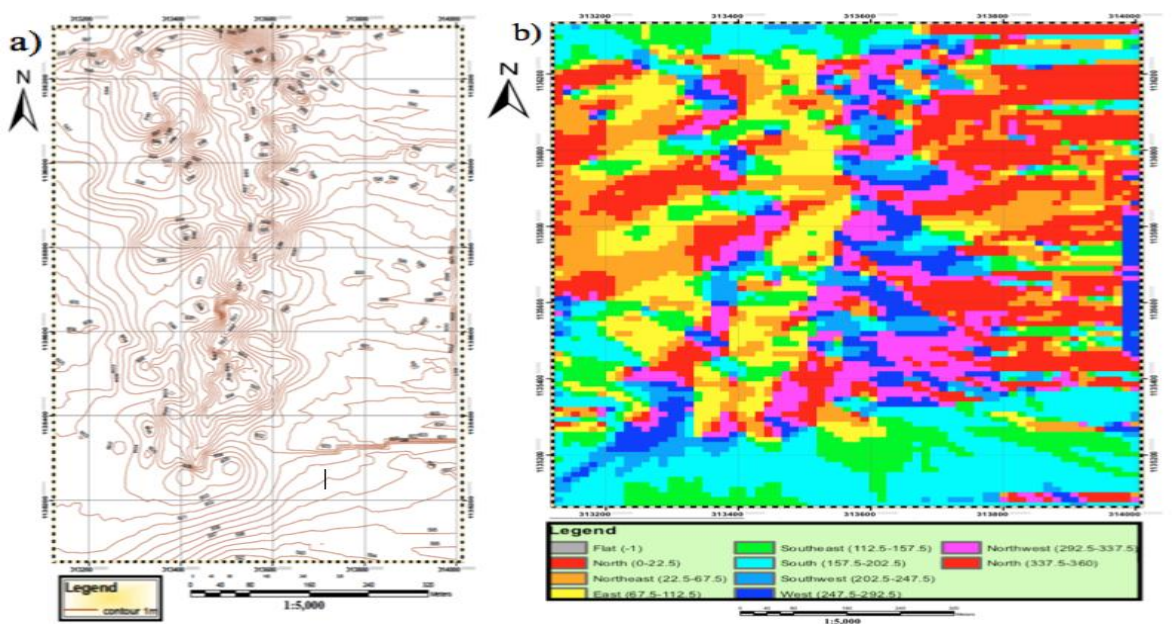

Figure 2: Map of the study area showing, a) Contour map, with contour interval of 1m, and b) Aspect Map showing the direction of flow.

\section{Results and Discussions}

The Digital Elevation Model (figure 1a) shows hills and lowlands in red and blues respectively. Higher grounds concentrate southward while low grounds to the north. This shows clearly the direction of flow which is northward, and the volume of water may be stagnated at the central northern part of the region. However, because the DEM gives a fairly homogenous charateristics of the terrain, we employ the watershed to see additionally where water can flow to, and areas that can suffer much during flood. Here, the northeast would be seriously affected compared to other regions (pink) while the southwest would be safer (Figure 1b).

a)

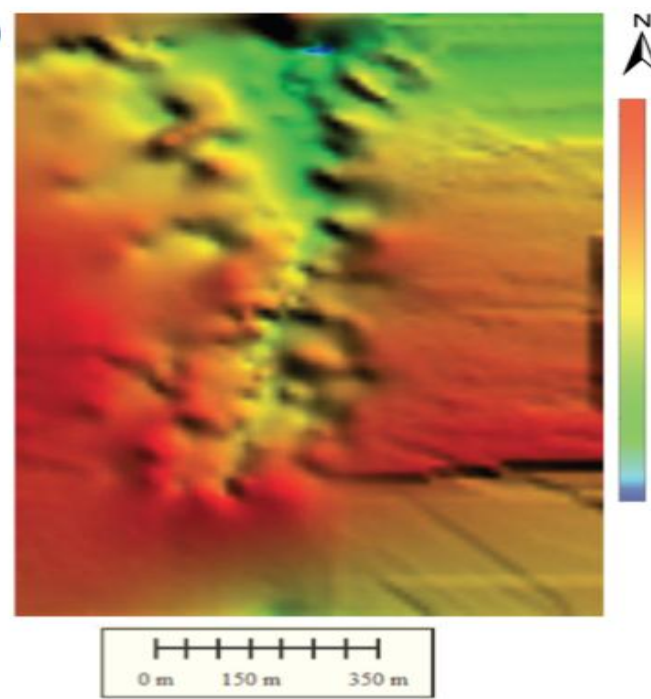

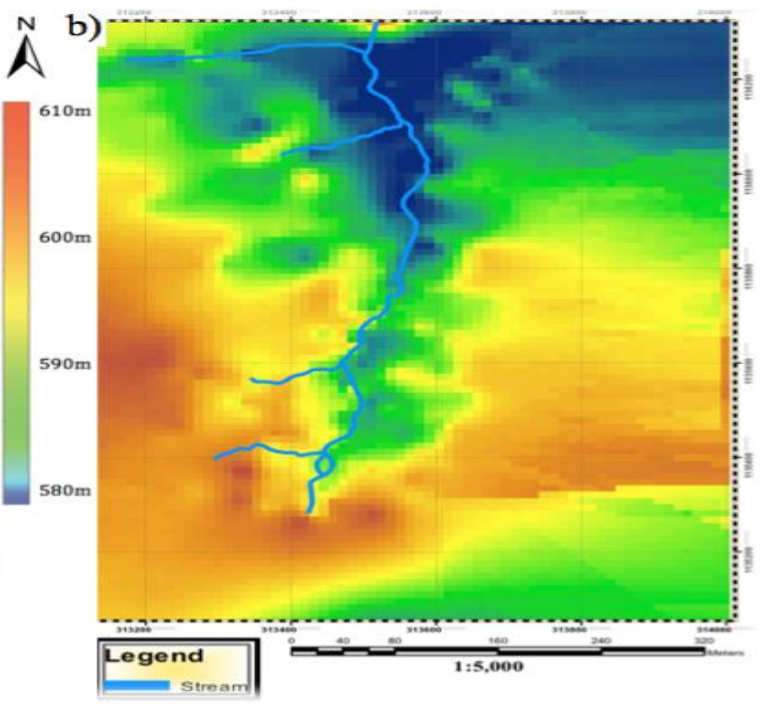

Figure 3: Map of the study area showing, a) Digital Terrain Model, and b) Overlay of Optimal River Network (ORN) on DEM.

We further this analysis by considering the contour map (Figure 2a). Variations of height to the middle of the region is much, indicating a slopy background to the lower ground. The quite homogenous contouring to the east and west indicate fairly flat surface. By indication, run off within the study area become srtonger to the centre, and that would increase river speed and enundation to the north. The soil material and amount of rainfall however are determinable conditions in this case. The Aspect Map (Figure 2b) shows the direction of flow of water when it rains, that is mostly northward (red). Addition flow directions that include northwest (pink) and east (yellow) appear to add to the northward flow and forcing much water to flow northeastward. Overall this pattern shows damped areas northwest of the area due to collection of water in poor drainange environment. It would be easier to view this using in a Digital Terrain Model (DTM) (Figure 3a).

The DTM provides heights of smooth surface without considering the difference between vegetation and built-up areas. The DTM amplifies the topography exhibited by contour and Aspect Maps. All water appears to drain northeastward along the lower topography, leaving a larger part of the region clear of waterlogging. It is however, important to compute a Optimal River Network (ORN) to help achieve the goal of determining a lasting solution to the flood and erosion in the study area. The ORN is computed and overlaid on 
the DEM (figure 3b). The calculation determines an ideal direction of flow of water out of the region, putting into consideration future planning and development. Existing small streams could be directed to a permanent flow network. This will help to minimise land loss due to erosion and reduce cost of developing building projects in the waterlogged area.

\section{Summary and Conclusion}

Geospatial analysis of surface relief features of waterlogged Barama area has been studied. Threedimensional coordinates of this region were collected using differential GPS. These coordinates are used to create Digital Elevation and Digital Terrain Models and their contingents comprising Watershed, Slope, Contours and Aspect to create an optimal river network. The interpolation was performed using arc GIS soltware with the following algorithms; Kriging, IDW (inverse distance weighted), natural neighbour and spline interpolations. An Optimal River Network is ultimately produced to link the minor streams into a bigger river, thereby ending water logging and bring an end to sporadic erosion.

The land features from the DEM and the visual analysis of the surface relief maps extracted from the DEM demonstrate how GIS capabilities can assist in controlling flood and erosion hazards. It is also possible to construct flood emergency reservouirs in case the waters do not have a flow direction.

It is recommended here that Local Government administration should have adequate and updated flood maps at all times to allow the floodway to be constructed, maintained and monitored. Floodways are channels and portions of the adjoining areas required to discharge the base flood without increasing flood heights more than 1 foot.

\section{Acknowledgement}

We thank the anonymous reviewers for their constructive comments and suggestions.

\section{References}

[1] Akintola, F. O., 1978. Hydrological consequences of urbanization: A case study of Ibadan city. Science Review, Vol. 1, Issue2, pp. 151.

[2] Boettle, M. , Kroop, J. ; Reiber, L. ; Roithmeier, O. ; Rybski, D. ; Walther, C., 2011. About the influence of elevation model quality on estimated flood damages: results from the Kalundberg case study. Natural hazards and Earth System Sciences; Vol. 11, Issue 12, pp. 3327

[3] Bukhari, A. S. and Muhammed, I., 2013. Geospatial Mapping of Health Facilities in Yola, Nigeria. Science, Toxicology And Food Technology, Vol. 7, Issue 3, PP 79-85.

[4] ESRI, 2003: IDRISI Guide to GIS and Image Processing. Clarks Lab, Clarks University, MA, USA.

[5] Konecny, G., 2003. Geoinformation:Remote sensing, photogrammetry and geographic information Inc, NewYork.

[6] Kumura, N., 2008. Application of Participatory G.I.S. for Rural Community Development and Local System in Sri Lanka. Sri Lanka Rural Development Seminar.

[7] Li, Z., Zhu, Q. And Gold, C., 2005. Digital terrain modelling: Principles and Methodology. CRC Press.

[8] Mark, D. M., 1988. Network Models in Geomorphology, in Anderson, M. G. (Ed.)., Modelling GeoJohn Widely, Chichester, England, pp. 73-97

[9] Podobnikar, T., 2008. Method for Visualizing Quality Assessment of a Digital Terrain Model. http://sapiens.revues.org/index738.html. Accessed on 29 November 2013.

[10] Ward, R. C., 1978. Flood Focal Problems in Geography. A Geographic Perspective. McMillan Press

Journal of Environmental

Ver 96.

systems.Taylor \& Francis

Level Spatial Planning

Boca Raton

Morphological Systems, 